\title{
Changes in the Incidence of Bronchopulmonary Dysplasia among Preterm Infants in a Single Center over 10 Years
}

\author{
Ga Won Jeon, $\mathrm{MD}, \mathrm{PhD}$
}

Department of Pediatrics, Inje University Busan Paik Hospital, Inje University College of Medicine, Busan, Korea

\section{ABSTRACT}

Purpose: Bronchopulmonary dysplasia (BPD) is one of the most fatal respiratory morbidities in preterm infants, causing adverse respiratory and neurodevelopmental outcomes. Despite advances in neonatal ventilator care, the incidence of BPD has been static or even increased. The purpose of this study was to evaluate the incidence of BPD in a single center over 10 years.

Methods: Preterm infants with gestational age (GA) $<30$ weeks who were admitted to Inje University Busan Paik Hospital from January 2009 to December 2018 and survived 28 days or more were enrolled. The incidence of BPD according to year and GA and the risk factors of BPD were evaluated.

Results: Among 629 infants, 521 infants who survived 28 days or more were enrolled (BPD group, $n=252$; non-BPD group, $n=269$ ). The incidence of BPD was $48.4 \%$, with moderate to severe BPD accounting for $13.9 \%$. In preterm infants with $\mathrm{GA} \leq 25,26$ to 27 , and 28 to 29 weeks, the incidences of BPD were $57.5 \%, 51.5 \%$, and $14.6 \%$, respectively, with moderate to severe BPD accounting for $23.8 \%, 10.5 \%$, and $3.7 \%$, respectively. The incidence of BPD decreased from $68 \%$ in 2009 to $34.3 \%$ in 2014. Subsequently, it increased. Surfactant re-dosing and patent ductus arteriosus were more frequent in the BPD group than in the non-BPD group.

Conclusion: BPD did not decrease over the previous 10 years despite advances in neonatal care.

Key Words: Bronchopulmonary dysplasia; Infant, premature; Infant, very low birth weight; Infant, extremely low birth weight; Infant, extremely premature

\section{INTRODUCTION}

Bronchopulmonary dysplasia (BPD) is one of the most fatal respiratory morbidities in preterm infants. BPD was first coined by Northway et al. ${ }^{1)}$ in 1967 as a chronic lung injury in preterm infants treated with oxygen and mechanical ventilation. Despite advances in neonatal ventilator care with reduced intubation and ventilation, increased early nasal continuous positive airway pressure (CPAP), and increased high flow nasal cannula (HFNC), the
Received: 23 August 2019

Revised: 5 November 2019

Accepted: 6 November 2019

Correspondence to: Ga Won Jeon, $\mathrm{MD}$, $\mathrm{PhD}$

Department of Pediatrics, Inje University Busan Paik Hospital, Inje Univer sity College of Medicine, 75 Bokji-ro, Busanjin-gu, Busan 47392, Korea

Tel: +82-51-890-6497

Fax: +82-51-890-5830

E-mail: iamgawon@hanmail.net

Copyright(c)

By Korean Society of Neonatology.

All right reserved.

This is an Open-Access article distributed under the terms of the Creative Commons At tribution Non-Commercial License (http:// creativecommons.org/licenses/by-nc/4.0), which permits unrestricted non-commercial use, distribution, and reproduction in any medium, provided the original work is pro perly cited. 
incidence of BPD has remained the same or even increased. This might be due in part to active resuscitation with improved survival of extremely low birth weight infants (ELBWIs, birth weight $<1,000$ g) and extreme preterm infants at greatest risk of $\mathrm{BPD}^{2)}$. The incidence of BPD (defined as oxygen requirement at 36 weeks of postmenstrual age [PMA]) in preterm infants with gestational age (GA) <29 weeks increased from $32 \%$ in 1993 to $45 \%$ in $2000^{3)}$, but it was seen to be static from 2008 to 2014 in another study ${ }^{4}$. The incidence of BPD among preterm infants with birth weight $<1,250$ g increased from $34 \%$ in $2001-2004$ to $39 \%$ in $2006^{5}$, and was $19 \%$ in very low birth weight infants (birth weight $<1,500 \mathrm{~g}$ ) and $30 \%$ in ELBWIs in another study ${ }^{6}$. BPD defined as oxygen dependency for $\geq 28$ days of life was reported in up to $58 \%$ of preterm infants with GA $<30$ weeks in 2000 to $2013^{7}$. Although the incidence of BPD differs according to centers, it shows an increasing trend.

BPD is related to increased mortality, cardiovascular impair ment, poor growth, long-term respiratory impairment, and poor neurodevelopmental outcome ${ }^{8)}$. Some preterm infants with severe BPD require supplemental oxygen or respiratory support for months or years. The increased number of infants with these comorbidities of BPD is an emerging social issue. Thus, it is im portant to reduce the incidence of BPD to improve outcomes of preterm infants.

The incidence of BPD in a single center over a long period can be used to evaluate the quality of neonatal care in a neonatal intensive care unit (NICU). Hence, the objective of this study was to evaluate the incidence of BPD by year in a single center over 10 years. The incidence of BPD according to GA was evaluated. Maternal and infant risk factors of BPD were also evaluated to sug gest ways to reduce BPD in preterm infants.

\section{MATERIALS AND METHODS}

Preterm infants with GA $<30$ weeks who were admitted to Inje University Busan Paik Hospital from January 2009 to December 2018 were enrolled. Preterm infants with chromosomal abnormalities or life-threatening major congenital malformations such as cardiac anomalies or pulmonary hypoplasia were excluded, as these conditions could be confounding factors by interfering with pulmonary function and survival. BPD was defined as an oxygen need or respiratory support at 36 weeks of PMA with oxy. gen treatment for at least the first 28 days ${ }^{9)}$. BPD was graded by the National Institute of Child Health and Human Development
(NICHD) consensus ${ }^{10)}$ : (1) mild BPD, breathing room air at 36 weeks of PMA or discharge; (2) moderate BPD, need for $<30 \%$ oxygen at 36 weeks of PMA or discharge; and (3) severe BPD, need for $\geq 30 \%$ oxygen with or without respiratory support at 36 weeks of PMA or discharge. Demographic factors and outcomes were compared between the BPD and non-BPD groups. Demographic factors included GA, birth weight, gender, Apgar score, maternal pregnancy-induced hypertension (PIH), maternal gestational diabetes mellitus (GDM), antenatal steroid therapy, and histologically confirmed chorioamnionitis. Outcomes included respiratory distress syndrome (RDS), surfactant re-dosing, patent ductus arteriosus (PDA), ligation of PDA, duration of invasive ventilation and non-invasive ventilation, total duration of mechanical ven tilation, duration of oxygen supply, and duration of hospital stay. The decision of surfactant re-dosing was left to the attending phy sician and was based on patient severity determined by chest radiography, blood gas analysis, and ventilator settings with need for $>40 \%$ oxygen. Rates of mortality, BPD, and moderate to severe BPD were compared according to year and GA $(\leq 25,26$ to 27 , and 28 to 29 weeks). For continuous variables with a normal distribution and homogeneous variance, $t$-tests were performed for comparing two groups. For variables without a normal distribution or without homogeneous variance, such as GA, the Mann-Whitney $U$-test was performed for two groups. For nominal variables, the chi-square test or Fisher's exact test was performed. The chisquare test for trend (Cochran-Armitage test) was performed for the annual change of incidence of BPD and mortality rate. All statistical analyses were performed using SPSS version 25.0 (IBM Co., Armonk, NY, USA). Data are given as mean \pm standard deviation. Statistical significance was considered at $P<0.05$.

\section{RESULTS}

\section{Demographic factors}

A total of 629 preterm infants under 30 weeks of GA were admitted. Six preterm infants with chromosomal abnormalities or major congenital malformations were excluded (one case of double outlet right ventricle with pulmonary stenosis; one case of lethal atelosteogenesis type 1; two cases of Edwards syndrome; two cases of multiple anomalies). After excluding 108 infants who were dead before 28 days, 521 preterm infants who survived 28 days or more days were enrolled (BPD group, $n=252$; non-BPD group, $n=269$ ). GA and birth weight were smaller in the BPD 
group than in the non-BPD group $(26.3 \pm 1.7$ weeks vs. $28.5 \pm 1.2$ weeks, $P<0.001 ; 846.4 \pm 209.7$ g vs. $1,202.4 \pm 255.0$ g, $P=0.013$, respec tively). The gender ratio or Apgar score at 1 minute was not significantly different between the two groups. However, the Apgar score at 5 minutes was lower in the BPD group than in the nonBPD group (6.4 \pm 1.2 vs. $7.1 \pm 1.0, P<0.001$ ). Maternal PIH, antenatal steroid therapy, or chorioamnionitis was not significantly different between the two groups. GDM was more frequent in the non-BPD group (Table 1).

\section{Outcomes}

Most patients had RDS, and surfactant re-dosing was more frequent in the BPD group than in the non-BPD group (19\% vs. $11.5 \%, P=0.020)$. Hemodynamically significant PDA (78.2\% vs. $46.1 \%, P<0.001)$ and ligation of PDA (40.9\% vs. $3.3 \%, P<0.001)$ were more frequent in the BPD group than in the non-BPD group. The total duration of ventilation (39.8 \pm 26.4 days vs. $6.2 \pm 5.5$ days, $P<0.001)$, duration of invasive ventilation (29.3 \pm 22.2 days vs. $4.3 \pm$ 4.1 days, $P<0.001$ ), and duration of oxygen supply (29.3 \pm 26.0 days vs. 4.1 \pm 5.8 days, $P<0.001$ ) were longer in the $\mathrm{BPD}$ group than in the non-BPD group. Hospital stays were also longer in the BPD group compared to the non-BPD group $(98.4 \pm 32.2$ days vs. $60.7 \pm$ 18.2 days, $P<0.001$ ) (Table 2 ).

\section{Incidence of BPD according to year}

Mortality, BPD, and moderate to severe BPD did not decrease according to year. A total of 131 infants died (108 infants died <28 days and 23 infants died $\geq 28$ days). Thus, the overall mortality rate of preterm infants with GA less than 30 weeks was $20.8 \%$. The mortality rate was the lowest in $2012(9.2 \%)$. The mortality rate was

Table 1. Demographic Factors

\begin{tabular}{lccr}
\hline Variable & $\begin{array}{c}\text { BPD } \\
(\mathrm{n}=252)\end{array}$ & $\begin{array}{c}\text { Non-BPD } \\
(\mathrm{n}=269)\end{array}$ & P-value \\
\hline Gestational age (wk) & $26.3 \pm 1.7$ & $28.5 \pm 1.2$ & $<0.001$ \\
Birth weight (g) & $846.4 \pm 209.7$ & $1,202.4 \pm 255.0$ & 0.013 \\
Male sex & $126(50)$ & $143(53.2)$ & 0.484 \\
Apgar score at 1 min & $4.0 \pm 1.3$ & $4.8 \pm 1.2$ & 0.526 \\
Apgar score at 5 min & $6.4 \pm 1.2$ & $7.1 \pm 1.0$ & $<0.001$ \\
PIH & $31(12.3)$ & $24(8.9)$ & 0.254 \\
GDM & $12(4.8)$ & $26(9.7)$ & 0.042 \\
Antenatal steroids therapy & $199(79)$ & $240(85.5)$ & 0.65 \\
Chorioamnionitis & $98(60.5)$ & $90(53.9)$ & 0.265 \\
\hline
\end{tabular}

Values are expressed as mean \pm standard deviation or number (\%). Abbreviations: BPD, bronchopulmonary dysplasia; PIH, pregnancyinduced hypertension; GDM, gestational diabetes mellitus. lower in 2017 compared to 2016. The overall incidence of BPD was $48.4 \%$. The incidence of moderate to severe BPD was $13.9 \%$. The incidence of BPD decreased from $68 \%$ in 2009 to $34.3 \%$ in $2014(P=$ 0.001). It then increased to $65.7 \%$ in 2017 and $55.9 \%$ in 2018. From 2012 to 2014, the incidence of BPD decreased while mortality, especially in preterm infants with GA $\leq 25$ weeks, increased. From 2016 to 2017, the incidence of BPD increased while mortality, especially in preterm infants with GA $\leq 25$ weeks, decreased. However, there was no statistically significant trend between the incidence of BPD and mortality rate of preterm infants with GA $\leq 25$ weeks. The incidence of moderate to severe BPD decreased in 2014 (7.8\%) but increased in 2016 (25\%) (Figure 1).

\section{Incidence of BPD according to GA}

Mortality and incidence of BPD, especially moderate to severe $\mathrm{BPD}$, decreased as GA increased. Mortality rate was $38.1 \%$ in those with GA $\leq 25$ weeks, $15.8 \%$ in those with GA 26 to 27 weeks, and $5.3 \%$ in those with GA 28 to 29 weeks $(P<0.001)$. In those with $\mathrm{GA} \leq 25,26$ to 27 , and 28 to 29 weeks, the incidences of BPD were $57.5 \%, 51.5 \%$, and $14.6 \%$, respectively $(P<0.001)$. The incidences of moderate to severe BPD were $23.8 \%, 10.5 \%$, and $3.7 \%$, in those with $\mathrm{GA} \leq 25,26$ to 27 , and 28 to 29 weeks, respectively $(P<0.001)$. Death or BPD was $95.6 \%$ in those with GA $\leq 25$ weeks, $66.3 \%$ in those with GA 26 to 27 weeks, and $19.9 \%$ in those with GA 28 to 29 weeks $(P<0.001)$. This meant that survival without BPD increased from $4.4 \%$ in those with GA $\leq 25$ weeks to $33.7 \%$ in those with GA 26 to 27 weeks, and then $80.1 \%$ in those with GA 28 to 29 weeks (Figure 2).

Table 2. Outcomes

\begin{tabular}{lrrr}
\hline Variable & $\begin{array}{c}\text { BPD } \\
(\mathrm{n}=252)\end{array}$ & $\begin{array}{r}\text { Non-BPD } \\
(\mathrm{n}=269)\end{array}$ & P-value* \\
\hline RDS & $252(99.2)$ & $265(98.5)$ & 0.687 \\
Surfactant re-dosing & $48(19.0)$ & $31(11.5)$ & 0.020 \\
PDA & $197(78.2)$ & $124(46.1)$ & $<0.001$ \\
Ligation of PDA & $103(40.9)$ & $9(3.3)$ & $<0.001$ \\
Total duration of mechanical & $39.8 \pm 26.4$ & $6.2 \pm 5.5$ & $<0.001$ \\
$\quad$ ventilation (d) & & & \\
Duration of invasive ventilation (d) & $29.3 \pm 22.2$ & $4.3 \pm 4.1$ & $<0.001$ \\
Duration of oxygen supply (d) & $29.3 \pm 26.0$ & $4.1 \pm 5.8$ & $<0.001$ \\
Hospital stay (d) & $98.4 \pm 32.2$ & $60.7 \pm 18.2$ & $<0.001$
\end{tabular}

Values are expressed as number $(\%)$ or mean \pm standard deviation.

*Adjusted by gestational age, birth weight.

Abbreviations: BPD, bronchopulmonary dysplasia; RDS, respiratory distress syndrome; PDA, patent ductus arteriosus. 


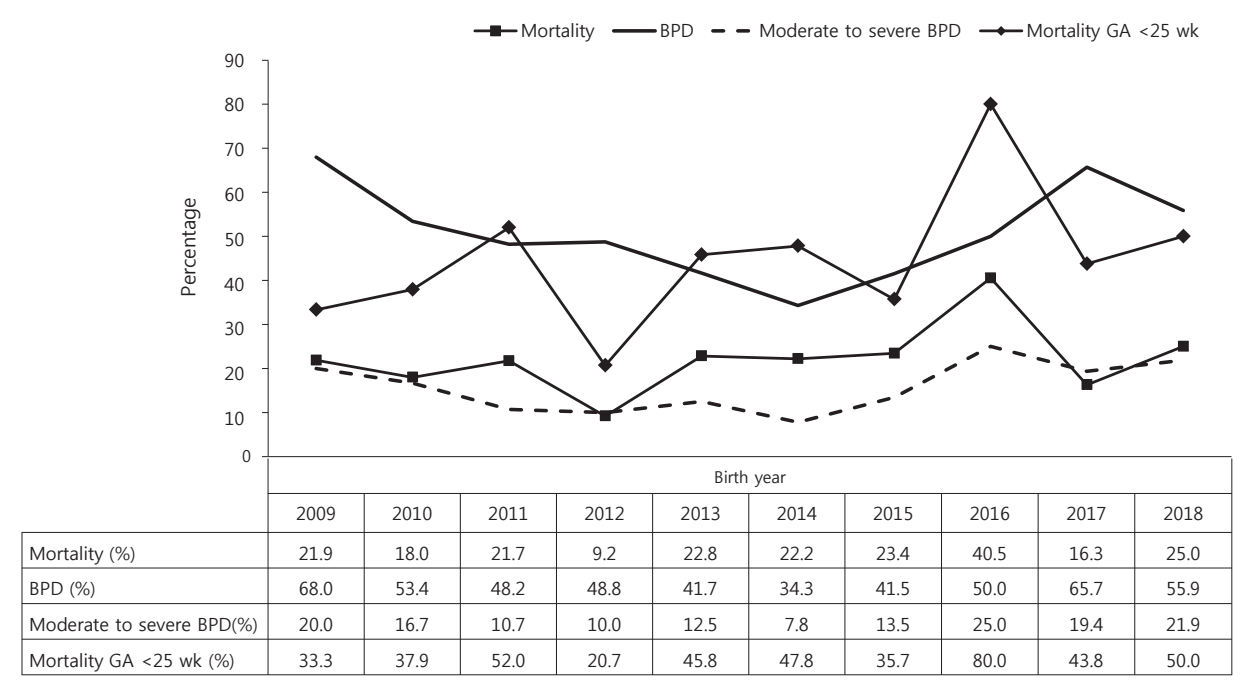

Figure 1. Incidence of bronchopulmonary dysplasia (BPD) according to year. The incidence of BPD decreased from $68 \%$ in 2009 to $34.3 \%$ in $2014(P=0.001)$, and then increased. From 2012 to 2014, BPD incidence decreased and the mortality rate of preterm infants with gestational age (GA) $\leq 25$ weeks increased. From 2016 to 2017, the incidence of BPD increased and mortality, especially preterm infants with GA $\leq 25$ weeks, decreased. Moderate to severe the incidence of BPD decreased in 2014 (7.8\%) and increased in 2016 (25\%).

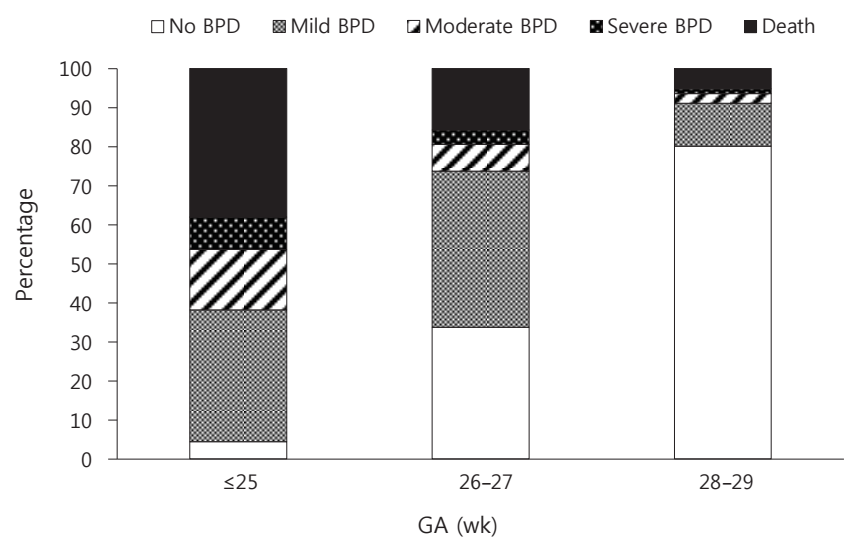

Figure 2. Incidence of bronchopulmonary dysplasia (BPD) ac cording to gestational age (GA). Mortality and incidence of BPD, especially moderate to severe BPD, decreased as GA increased. The mortality rate was $38.1 \%$ in those with GA $\leq 25$ weeks, $15.8 \%$ in those with GA 26 to 27 weeks, and 5.3\% in those with GA 28 to 29 weeks $(P<0.001)$. In those with $\mathrm{GA} \leq 25,26$ to 27 , and 28 to 29 weeks, the incidences of BPD were $57.5 \%, 51.5 \%$, and $14.6 \%$, respectively $(P<0.001)$. The corresponding incidences of moderate to severe BPD were $23.8 \%, 10.5 \%$, and $3.7 \%$, respectively $(P<0.001)$. Survival without BPD increased from $4.4 \%$ in GA $\leq 25$ weeks to $33.7 \%$ in GA 26 to 27 weeks and then $80.1 \%$ in GA 28 to 29 weeks $(P<0.001)$.

\section{DISCUSSION}

BPD is associated with adverse respiratory outcomes and poor neurodevelopmental outcomes in preterm infants ${ }^{11-13)}$. In particular, infants with severe BPD who need respiratory support at
36 weeks of PMA are more likely to be neurodevelopmentally im paired at 2 years of age than those with mild to moderate $\mathrm{BPD}^{7}$. Various drugs have been used to treat BPD over the past 20 years. However, only a few drugs have shown to be effective ${ }^{14,15)}$. Currently, there is no drug approved by the U.S. Food and Drug Ad ministration (FDA) to prevent $\mathrm{BPD}^{16)}$. Aggressive surfactant instillation has been used to reduce BPD. Surfactants have been administered as prophylactic therapy in preterm infants with GA $<30$ weeks or with a birth weight $\leq 1,250 \mathrm{~g}$ in Korea since January $2011^{17)}$. Less invasive ventilators ${ }^{18,19)}$, less invasive surfactant administration ${ }^{20}$, and even surfactant administration without intubation $^{21)}$ have been tried to reduce BPD. Despite a variety of efforts as previously mentioned, the incidence of BPD has not decreased.

The definition of BPD was revised several times after its first description by Northway et al. ${ }^{1)}$ in 1967 . Shennan et al. ${ }^{22)}$ have suggested that oxygen requirement at 36 weeks of PMA is more predictive of an adverse respiratory outcome than oxygen requirement for $\geq 28$ days of life. The definition of BPD was revised in $2000^{10)}$ at a workshop organized by NICHD on the basis of respiratory status at 36 weeks of PMA. This has become the most widely used definition for $\mathrm{BPD}^{10)}$. The physiologic definition of BPD is also used in infants at 36 weeks of PMA with an oxygen reduction test to confirm oxygen requirement ${ }^{23)}$.

The incidence of BPD differs according to different centers. Inter-center differences may be caused by different definitions 
used for BPD in each center. The overall incidence of BPD was $48.4 \%$, with moderate to severe BPD accounting for $13.9 \%$ in this study from 2009 to 2018. A similar result was reported by another study that the incidence of BPD was $42 \%$, with moderate to severe BPD at $19 \%{ }^{24)}$. According to a nationwide survey from 52 NICUs in Korea in $2012^{25)}$, the incidence of BPD was $28 \%$ and that of moderate to severe BPD was $16 \%$ in infants with GA $<32$ weeks. This incidence of BPD was lower than in the present study. However, the GA of the enrolled preterm infants was younger in the present study ( $\mathrm{GA}<30$ weeks vs. $\mathrm{GA}<32$ weeks). In another nationwide study from 55 NICUs in Korea in $2015^{26)}$, the incidence of mo derate to severe BPD increased to $33 \%$ in preterm infants with GA $<32$ weeks. This incidence of BPD was higher than in the present study. The incidence of BPD in preterm infants with GA $<30$ weeks from 2000 to 2013 was $58 \%$ as reported by Malavolti et al. ${ }^{7)}$, which was higher than that in the present study. In a large neonatal network dataset, the incidence of BPD defined as oxy. gen requirement at 36 weeks of PMA (corresponding to moderate to severe BPD) increased from 19\% in 1990 to 1991 to $23 \%$ in 1995 to 1996 and $22 \%$ in 1997 to 2002 by the NICHD Neonatal Research Network $^{27)}$. The improved survival of ELBWIs was suggested as the cause of the steady incidence of BPD. On the contrary, the incidence of BPD defined as oxygen requirement at 36 weeks of PMA decreased from $36.6 \%$ in 2001 to $26.8 \%$ in 2003 based on the Vermont Oxford Network ${ }^{28)}$.

The incidence of BPD decreased from $68 \%$ in 2009 to $34.3 \%$ in 2014. It then increased again thereafter in the present study. From 2009 to 2011, BPD incidence decreased while mortality of extreme preterm infants increased. Mortality, especially mortality of extreme preterm infants, was lowest in 2012. However, the incidence of BPD and moderate to severe BPD did not increase, and was rather static. From 2012 to 2014, the BPD incidence de creased while the mortality of extreme preterm infants increased in this study. On the contrary, from 2016 to 2017, the incidence of BPD increased while the survival of extreme preterm infants improved. This inverse proportion of BPD and mortality rate can be explained by the theory that BPD is increased by the improved survival of extreme preterm infants at greatest risk of $\mathrm{BPD}^{29)}$. How ever, there was no statistical significance between the incidence of BPD and mortality rate of preterm infants with GA $\leq 25$ weeks in the present study. The lowest mortality without increasing BPD in 2012 may partly be explained by improved neonatal intensive care with enough neonatologists. There were three attending physicians in our NICU in 2012. The incidence of BPD increased from 2014. This may be partly explained by the increased use of HFNC in our NICU, which was introduced in 2013 to reduce the use of nasal CPAP. However, there is a worrisome trend of using HFNC instead of oxygen or using HFNC in infants who do not absolutely need it.

A younger GA was a risk factor for BPD in this study, which was expected. Surfactant re-dosing, PDA, and ligation of PDA were also risk factors for BPD in this study. Surfactant re-dosing reflects a poor lung status in early postnatal ages. Longstanding PDA increases pulmonary blood flow and causes pulmonary edema, decreases lung compliance, and increases lung inflammation. Hence, PDA can adversely affect BPD. However, whether hemodynamically significant PDA is one of the risk factors of BPD is controversial ${ }^{30}$. Histologically confirmed chorioamnionitis was not significantly different between the two groups in this study. Our hospital started reviewing placental histology in late 2010 and early 2011; therefore, this result might be due to missing data that could have affected our statistical power.

The strength of this study is that it was a single center study. There were no inter-center differences in the definition for BPD. In addition, the same diagnostic criteria for BPD were used. There were no differences according to caregivers' practice styles, such as weaning of ventilators, oxygen, or targeted oxygen saturation. Since uniform diagnostic criteria for BPD and uniform care practice were used, the real incidence of BPD could be evaluated. However, this study also has limitations. The NICU was closed for a period of time without a neonatologist. This might have affected the number of admissions and the outcomes of preterm infants, especially extreme preterm infants at the limit of viability. The physiologic definition of BPD, which could reduce the variation and incidence of BPD, was not used in this study. As such, there are chances of overestimation and reporting inaccurate inci dences of BPD.

In conclusion, the incidence of BPD did not decrease over a ten-year period despite advances in neonatal care. the incidence of BPD decreased from 2009 to 2014, but then increased. The overall incidence of BPD was $48.4 \%$, with moderate to severe BPD accounting for $13.9 \%$.

\section{ARTICLE INFORMATION}

\section{Ethical statement}

The study protocol was reviewed and approved by the Institu- 
tional Review Board of Inje University Busan Paik Hospital, Busan, Korea (identification code: 19-0138) in accordance with the Declaration of Helsinki. The Institutional Review Board waived the need for informed consent for this retrospective chart review.

\section{Conflicts of interest}

No potential conflict of interest relevant to this article was reported.

\section{Author contributions}

Conception or design: G.W.J.

Acquisition, analysis, or interpretation of data: G.W.J.

Drafting the work or revising: G.W.J.

Final approval of the manuscript: G.W.J.

\section{ORCID}

Ga Won Jeon https://orcid.org/0000-0002-8206-9727

\section{Acknowledgments}

This work was supported by 2019 Inje University Busan Paik Hospital research grant.

\section{REFERENCES}

1. Northway WH Jr, Rosan RC, Porter DY. Pulmonary disease following respirator therapy of hyaline-membrane disease. Bronchopulmonary dysplasia. N Engl J Med 1967;276:357-68.

2. Hahn WH, Chang JY, Chang YS, Shim KS, Bae CW. Recent trends in neonatal mortality in very low birth weight Korean infants: in comparison with Japan and the USA. J Korean Med Sci 2011; 26:467-73.

3. Stoll BJ, Hansen NI, Bell EF, Walsh MC, Carlo WA, Shankaran S, et al. Trends in care practices, morbidity, and mortality of extremely preterm neonates, 1993-2012. JAMA 2015;314:1039-51.

4. Baud O, Maury L, Lebail F, Ramful D, El Moussawi F, Nicaise C, et al. Effect of early low-dose hydrocortisone on survival without bronchopulmonary dysplasia in extremely preterm infants (PREMILOC): a double-blind, placebo-controlled, multicentre, randomised trial. Lancet 2016;387:1827-36.

5. Ambalavanan N, Walsh M, Bobashev G, Das A, Levine B, Carlo WA, et al. Intercenter differences in bronchopulmonary dysplasia or death among very low birth weight infants. Pediatrics 2011;127:e106-16.

6. Stevenson DK, Wright LL, Lemons JA, Oh W, Korones SB, Papile LA, et al. Very low birth weight outcomes of the National Institute of Child Health and Human Development Neonatal
Research Network, January 1993 through December 1994. Am J Obstet Gynecol 1998;179(6 Pt 1):1632-9.

7. Malavolti AM, Bassler D, Arlettaz-Mieth R, Faldella G, Latal B, Natalucci G. Bronchopulmonary dysplasia-impact of severity and timing of diagnosis on neurodevelopment of preterm infants: a retrospective cohort study. BMJ Paediatr Open 2018;2: e000165.

8. Majnemer A, Riley P, Shevell M, Birnbaum R, Greenstone H, Coates AL. Severe bronchopulmonary dysplasia increases risk for later neurological and motor sequelae in preterm survivors. Dev Med Child Neurol 2000;42:53-60.

9. Kinsella JP, Greenough A, Abman SH. Bronchopulmonary dys plasia. Lancet 2006;367:1421-31.

10. Jobe AH, Bancalari E. Bronchopulmonary dysplasia. Am J Respir Crit Care Med 2001;163:1723-9.

11. Jeng SF, Hsu CH, Tsao PN, Chou HC, Lee WT, Kao HA, et al. Bronchopulmonary dysplasia predicts adverse developmental and clinical outcomes in very-low-birthweight infants. Dev Med Child Neurol 2008;50:51-7.

12. Karagianni P, Tsakalidis C, Kyriakidou M, Mitsiakos G, Chatziioanidis $\mathrm{H}$, Porpodi M, et al. Neuromotor outcomes in infants with bronchopulmonary dysplasia. Pediatr Neurol 2011;44:40-6.

13. Synnes A, Luu TM, Moddemann D, Church P, Lee D, Vincer $\mathrm{M}$, et al. Determinants of developmental outcomes in a very preterm Canadian cohort. Arch Dis Child Fetal Neonatal Ed 2017;102:F235-4.

14. Baveja R, Christou H. Pharmacological strategies in the pre vention and management of bronchopulmonary dysplasia. Semin Perinatol 2006;30:209-18.

15. Tropea K, Christou H. Current pharmacologic approaches for prevention and treatment of bronchopulmonary dysplasia. Int J Pediatr 2012;2012:598606.

16. Beam KS, Aliaga S, Ahlfeld SK, Cohen-Wolkowiez M, Smith PB, Laughon MM. A systematic review of randomized controlled trials for the prevention of bronchopulmonary dysplasia in infants. J Perinatol 2014;34:705-10.

17. Jeon GW, Oh M, Sin JB. Efficacy of surfactant-TA, calfactant and poractant alfa for preterm infants with respiratory distress syndrome: a retrospective study. Yonsei Med J 2015;56:433-9.

18. Morley CJ, Davis PG, Doyle LW, Brion LP, Hascoet JM, Carlin JB, et al. Nasal CPAP or intubation at birth for very preterm infants. N Engl J Med 2008;358:700-8.

19. SUPPORT Study Group of the Eunice Kennedy Shriver NICHD Neonatal Research Network, Finer NN, Carlo WA, Walsh MC, Rich W, Gantz MG, et al. Early CPAP versus surfactant in extremely preterm infants. N Engl J Med 2010;362:1970-9.

20. Stevens TP, Harrington EW, Blennow M, Soll RF. Early surfactant administration with brief ventilation vs. selective surfactant and continued mechanical ventilation for preterm infants with or at risk for respiratory distress syndrome. Cochrane Database Syst 
Rev 2007;4:CD003063.

21. Kanmaz HG, Erdeve O, Canpolat FE, Mutlu B, Dilmen U. Sur factant administration via thin catheter during spontaneous breathing: randomized controlled trial. Pediatrics 2013;131: e502-9.

22. Shennan AT, Dunn MS, Ohlsson A, Lennox K, Hoskins EM. Abnormal pulmonary outcomes in premature infants: predic tion from oxygen requirement in the neonatal period. Pediatrics 1988;82:527-32.

23. Walsh MC, Yao Q, Gettner P, Hale E, Collins M, Hensman A, et al. Impact of a physiologic definition on bronchopulmonary dysplasia rates. Pediatrics 2004;114:1305-11.

24. Kim SH, Lee KH, Lee SH, You DK, Choi SJ, Hwang JH, et al. The comparison of severity according to preceding causes of bronchopulmonary dysplasia in very low birth weight infants. J Korean Soc Neonatol 2003;10:47-54.

25. Choi CW, Kim BI, Kim EK, Song ES, Lee JJ. Incidence of bronchopulmonary dysplasia in Korea. J Korean Med Sci 2012;27:91421.
26. Jo HS, Cho KH, Cho SI, Song ES, Kim BI. Recent changes in the incidence of bronchopulmonary dysplasia among very-lowbirth-weight infants in Korea. J Korean Med Sci 2015;30 Suppl 1:S81-7.

27. Fanaroff AA, Stoll BJ, Wright LL, Carlo WA, Ehrenkranz RA, Stark AR, et al. Trends in neonatal morbidity and mortality for very low birthweight infants. Am J Obstet Gynecol 2007;196:147.

28. Payne NR, LaCorte M, Karna P, Chen S, Finkelstein M, Goldsmith JP, et al. Reduction of bronchopulmonary dysplasia after participation in the Breathsavers Group of the Vermont Oxford Network Neonatal Intensive Care Quality Improvement Collaborative. Pediatrics 2006;118 Suppl 2:S73-7.

29. Smith VC, Zupancic JA, McCormick MC, Croen LA, Greene J, Escobar GJ, et al. Trends in severe bronchopulmonary dysplasia rates between 1994 and 2002. J Pediatr 2005;146:469-73.

30. Kalikkot Thekkeveedu R, Guaman MC, Shivanna B. Broncho pulmonary dysplasia: a review of pathogenesis and pathophysiology. Respir Med 2017;132:170-7. 